\title{
Microbial contaminants in wild harvested and traded edible long-horned grasshopper, Ruspolia differens (Orthoptera: Tettigoniidae) in Uganda
}

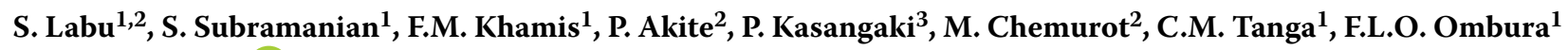 \\ and J.P. Egonyu ${ }^{*}$ iD \\ ${ }^{1}$ International Centre of Insect Physiology and Ecology, P.O. Box 30772-00100, Nairobi, Kenya; ${ }^{2}$ Department of Zoology, \\ Entomology and Fisheries Sciences, College of Natural Sciences, Makerere University, P.O. Box 7062, Kampala, Uganda; \\ ${ }^{3}$ National Livestock Resources Research Institute, P.O. Box 5704, Kampala, Uganda; pegonyu@icipe.org
}

Received: 8 July 2020 / Accepted: 2 February 2021

(C) 2021 Wageningen Academic Publishers

OPEN ACCESS CC) (i) (9) RESEARCH ARTICLE

\begin{abstract}
This study investigated the relative abundance and identity of microbial contaminants of the edible long-horned grasshopper (Ruspolia differens) harvested from the wild and traded in informal markets in Uganda, to reveal high health risk points. Raw samples of whole $R$. differens were collected from wild vegetation, trapping sites and markets. Additionally, samples of plucked and deep-fried ready-to-eat $R$. differens were collected from the markets. The samples were cultured on standard media for microbial quantification, and pure cultures were characterised using molecular techniques. Bacterial and fungal counts in deep fried ready-to-eat $R$. differens were $\sim 3$ - and 2-fold lower, respectively, than in raw samples. Loads of these microbes in deep fried insects were within recommended food safety limits. The highest bacterial counts were detected in whole $R$. differens samples from the market followed by trapping points. The fungal counts in the raw $R$. differens were comparable across the sampling points. The bacterial and fungal counts in $R$. differens in Kampala were not influenced by district of origin. Seven species of bacteria and seven species of fungi were recorded in $R$. differens samples. The microbial species were most diverse in samples from trapping points and least diverse in the deep-fried insects. The key pathogenic bacteria detected in marketed $R$. differens were Staphylococcus sciuri, Acinetobacter baumannii and Serratia marcescens, all of which were absent in wild-caught whole insects. Our results demonstrate that $R$. differens obtained at the trapping sites and markets are contaminated with potentially harmful microbes, therefore they require processing through deep frying to minimise health risks associated with their consumption. Further studies are warranted to elucidate specific handling practices at distribution and trapping points which may prevent introduction of microbes into $R$. differens.
\end{abstract}

Keywords: markets, food safety, food processing, nsenene, trapping sites

\section{Introduction}

Edible insects have gained global recognition in recent years as alternative sources of food and feed with a comparable or superior nutritional content than conventional animal products (Dobermann et al., 2017; Kelemu et al., 2015; Van Huis, et al., 2013). The rich nutritional value of edible insects coupled with high moisture content provide a conducive environment for microbial contamination, survival and growth (Klunder et al., 2012; Van Huis, et al., 2013). Microorganisms can also be introduced along the food handling chain, causing food spoilage or disease outbreaks (Ng'ang'a et al., 2019; Ssepuuya et al., 2019). Intrinsic factors (e.g. $\mathrm{pH}$, moisture content and water activity) and extrinsic factors (e.g. temperature, relative humidity, number and type of microorganisms present) influence microbial survival and growth in foods (Charpe et al., 2019; Garofalo et al., 2019). The number and type of microorganisms in foods is highly influenced by the environment where the food originated and the sanitary conditions under which it is handled and processed (Belluco et al., 2013; Van Huis et al., 2013). Also, the symbiotic association of many insect species with some fungi and bacteria (Engels and Moran, 2013) enables them to thrive 
and survive in the insects' gut (Colman et al., 2012). This also possibly causes spoilage once the insect dies.

Several studies have highlighted the presence of different genera of bacteria and fungi in fresh and processed (readyto-eat) insects e.g. the migratory locust, Locusta migratoria L (Orthoptera: Acrididae) and mealworm, Tenebrio molitor L (Coleoptera: Tenebrionidae) (Garofalo et al., 2017; Stoops et al., 2016); crickets, Acheta domesticus L and Gryllodes sigillatus (Walker) (Orthoptera: Gryllidae) (Osimani et al., 2017; Vandeweyer et al., 2017); and the long-horned grasshopper, Ruspolia differens (Serville) (Orthoptera: Tettigoniidae) (Ng'ang'a et al., 2019; Ssepuuya et al., 2019). Counts of total aerobic microbes, yeasts and moulds higher than the maximum standard limits set out in standards for edible insects (KEBS, 2020; Stoops et al., 2016; UNBS, 2020 ) have been reported in wild harvested raw $R$. differens (Ng'ang'a et al., 2019; Ssepuuya et al., 2019).

In East Africa, the long-horned grasshopper, $R$. differens commonly called nsenene forms a major part of the food culture, constituting 5-10\% protein intake of some populations (Ayieko et al., 2012; Kinyuru et al., 2010). This insect exists predominantly in two colour morphs, i.e. light brown and light green (Leonard et al., 2020). Swarms of $R$. differens occur twice a year during rainy seasons (Agea et al., 2008; Mmari et al., 2017; Ssepuuya et al., 2017). The insects are harvested at night using high light intensity fluorescent bulbs to attract them onto slanting silver iron sheets that slide the catch into harvesting drums (Okia et al., 2017). Materials such as moist cassava flour are applied on the drum walls and iron sheets to make them slippery to prevent the insects from escaping. These materials may predispose the trapped insects to contamination by harmful microbes hence reducing their quality and increasing health risks to consumers. In Uganda, Masaka district is among the leading sites of harvesting $R$. differens while Kampala city is the hub of trade in these grasshoppers originating from different locations (Agea et al., 2008; Ssepuuya et al., 2017). These locations are therefore ideal for investigation of microbial contamination of $R$. differens along its value chain.

After harvesting, trappers manually transfer $R$. differens from the drums into aerated polythene/nylon/sisal bags. Most of the harvest is then sold to dealers who transport whole insects by public means to distribution points in other districts. In such points, the insects which are inactive due to anoxia are sold to retailers who then process them before selling to final consumers or other middle persons. Retailers with large quantities of raw $R$. differens kill and preserve some insects by freezing before processing. Processing of $R$. differens is usually carried out for value addition and to increase on shelf stability, but food processing methods may impact on safety and nutritional value (Bokulich et al., 2016; Nyangena et al., 2020). Processing R. differens begins with sorting out non-target insects and plucking (removal of wings, antennae and legs) followed by washing with clean water. To speed up the cleaning process, materials such as wood ash, maize flour or cassava flour are employed to increase friction (Ssepuuya et al., 2019). The plucked grasshoppers are usually deep fried (to increase the shelf life (Ssepuuya et al., 2016)), cooled and sold ready-to-eat or stored in cardboard boxes. The involvement of several people during the post-harvest handling processes under different environmental conditions is likely to compromise $R$. differens quality and safety (Ssepuuya et al., 2019). Therefore, this study aimed at quantifying and identifying bacterial and fungal contaminants at different points of the food handling chain for wild harvested $R$. differens in Uganda, to reveal high health risk points. The hypotheses tested were: (1) there is no difference in the loads and identity of bacteria and fungi in raw whole $R$. differens samples from wild vegetation, trapping sites and at markets, as well as processed (raw plucked and deep fried) samples from markets; (2) there is no difference in the loads of bacteria and fungi in $R$. differens from markets in Masaka and Kampala districts; and (3) loads of bacteria and fungi in $R$. differens distributed in Kampala are not influenced by their district of origin.

\section{Materials and methods}

\section{Study area}

This study was conducted in two purposively selected districts of Masaka and Kampala in central Uganda. From Masaka district, four R. differens trapping points (Kitaka, Nyendo-villa road, Kayirikiti A, Kayirikiti B) and three markets selling the insects (Nyendo, Masaka Municipal and Ssaza) were purposively sampled. Masaka district has a bi-modal rainfall pattern with peaks experienced between March to May and September to December. The mean annual rainfall in Masaka ranges between 1,100 and $1,200 \mathrm{~mm}$ with temperatures ranging between 18 and $28^{\circ} \mathrm{C}$ (Masaka District Local Government, 2020). In Kampala district, $R$. differens was sampled from two distribution points (Katwe and Busega) and three markets (Kalerwe, Nakasero and Kasubi). Kampala district has a bimodal rainfall regime with peaks experienced in March to May and September to November, with mean annual rainfall ranging between 1,750 and 2,000 $\mathrm{mm}$ and temperatures of $17-28^{\circ} \mathrm{C}$ (NEMA, 2014). During data collection, coordinates from sampling points were taken with a Global Positioning System (GPS) (GARMIN eTrex 20X, Garmin Ltd, Olathe, KS, USA) and plotted on Arc Map using the Arc GIS software version 10.3 (Esri Eastern Africa Ltd, Naiobi, Kenya) (Figure 1).

\section{Sampling design and sample collection}

$R$. differens samples weighing $200 \mathrm{~g}$ per batch were collected on 14 and 15 June (first season) and 23 and 24 November (second season) 2019 from each sampling point in Masaka 


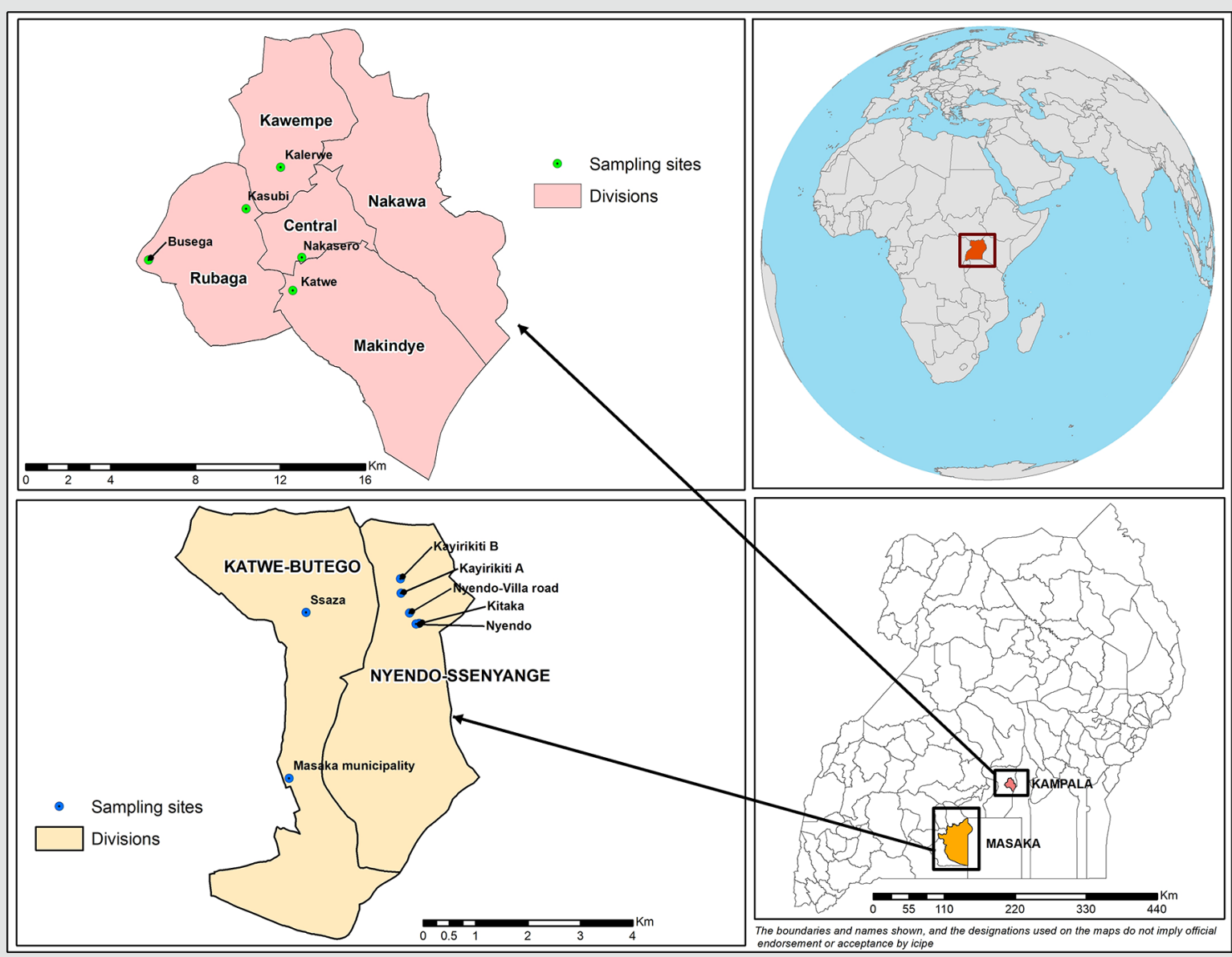

Figure 1. Locations of Ruspolia differens sampling sites in Masaka and Kampala, central Uganda in 2019.

and Kampala districts. In Masaka, a total of 36 batches were obtained in each season as follows: (1) 9 batches (3 replicates per site) of live whole $R$. differens collected from wild vegetation using a sweep net at Nyendo-vila road, Kayirikiti A and Kayirikiti B; (2) 9 batches (3 replicates per site) of raw whole $R$. differens randomly sampled from harvesting drums at Kayirikiti A, Nyendo-vila road and Kitaka trapping points; and (3) 9 batches of raw plucked and 9 batches of deep fried $R$. differens (3 replicates of each type) at Nyendo, Masaka Municipal and Ssaza markets. A total of 72 batches were therefore sampled in Masaka in the two seasons. In Kampala, 9 batches of raw whole $R$. differens from distribution points of Busega (3 replicates originating from Fort-portal district) and Katwe (3 replicates each from grasshoppers originating from Kasese and Kabale districts) were purchased in the second season only because samples collection in the first season commenced when supplies at the distribution points had become scarce. In addition, 18 batches of $R$. differens were purchased from Kampala in each season as follows: 9 batches of raw plucked and 9 batches of deep-fried $R$. differens (3 replicates of each type per market) from Nakasero, Kalerwe and Kasubi markets. In total, 27 batches of plucked and deep-fried $R$. differens were obtained from Kampala in the two seasons. Each $R$. differens samples obtained was immediately placed in a sterile zip lock bag, kept in a cool box with flaked ice and transported to Makerere University, Department of Zoology, Entomology and Fisheries Sciences for preservation in Haier deep freezer HCF-300HTQ at $-20^{\circ} \mathrm{C}$ (Haier deep freezer, India) prior to transportation for microbial analysis at the International Centre of Insect Physiology and Ecology (icipe), Nairobi.

\section{Microbiological analyses}

From each batch of $R$. differens samples, $5 \mathrm{~g}$ were ground using a sterile pestle and mortar. These homogenates were resuspended in $45 \mathrm{ml}$ buffered saline in $50 \mathrm{ml}$ falcon tubes to form stock solutions. Serial dilution was done using $1 \mathrm{ml}$ from the stock solution into another $9 \mathrm{ml}$ phosphate-buffered saline in a $27 \mathrm{ml}$ universal tube using a sterile pipette. The 10 -fold dilution was repeated to obtain between $10^{-2}$ to $10^{-8}$ and $10^{-2}$ to $10^{-5}$ for isolation and analyses of bacteria and fungi, respectively (Ssepuuya et al., 2019). Isolation and analyses of bacteria and fungi were done in triplicates on four different types of media 
which included MacConkey agar and nutrient agar for bacteria, and potato dextrose agar and Sabouraud dextrose agar for fungi (Gatheru et al., 2019). After 5 days, fungal colony counts were conducted with the aid of a dissecting microscope. Sub-culturing was done for plates with mixed colonies to obtain pure colonies. For bacteria, colony counts for individual plates were obtained after 48 hours. The counting was aided by a hand-held tally counter. The bacterial and fungal counts were computed and expressed as colony forming units per gram (cfu/g) according to Omoya and Akinyosoye (2013).

\section{Biochemical characterisation}

Pure bacterial isolates were classified by gram staining (Public Health England, 2019). For each isolate, a smear was prepared, fixed by heating gently and the slide flooded with $0.5 \%$ crystal violet dye. After 30 seconds, the slide was rinsed using water, flooded with $1 \%$ Lugol's iodine and covered with fresh iodine. The smear was then decolorised using 95\% ethanol, rinsed with water and flooded with $0.1 \%$ counterstain safranin. The slide was washed, blot dried and examined using oil immersion objective under a total magnification of 1000× (Leica EZ4HD Stereo microscope, Leica Microsystems Inc., Heerbrugg, Switzerland). Pure cultures were later identified to species level using molecular techniques.

\section{DNA extraction}

Fungal colonies from pure cultures were harvested by scrapping mycelia/spores using a sterile blade into $1.5 \mathrm{ml}$ Eppendorf tubes, each containing three sterile beads and genomic DNA extracted using the plant DNA extraction kit (Bioline, London, UK) following the manufacturer's protocol. On the other hand, pure bacterial isolates were aseptically inoculated into $7 \mathrm{ml}$ Luria broth in sterile $50 \mathrm{ml}$ Falcon tubes placed into an Innova 44 incubator shaker (Eppendorf, Hamburg, Germany) set at $180 \mathrm{rpm}$ and $37^{\circ} \mathrm{C}$ for 18 hours. The cells were then harvested by centrifugation at 2,000 relative centrifugal force for $3 \mathrm{~min}$ into $1.5 \mathrm{ml}$ Eppendorf tubes. Bacterial DNA was then extracted using the isolate II Genomic DNA Kit (Bioline) following the manufacturer's protocol.

\section{PCR-amplification}

Polymerase chain reaction (PCR) amplification of fungi was carried out as described by Gatheru et al. (2019). Briefly, all PCR reactions were carried out in a final $20 \mu$ l volume containing $5 \times$ MyTaq reaction buffer (Bioline) $(5 \mathrm{mM} \mathrm{dNTPs,}$ $15 \mathrm{mM} \mathrm{MgCl}{ }_{2}$ stabilisers and enhancers), $0.5 \mathrm{pmol} / \mu \mathrm{l}$ of each primer (ITS5 ( 5 ' TCCTCCGCTTGATATTGATATGC $3^{\prime}$ ) and ITS4 (5' GGAAGTAAAAGTCGTAACAAGG 3') (White et al., 1990)), $0.25 \mathrm{mM} \mathrm{MgCl}_{2}, 0.0625 \mathrm{U} / \mu \mathrm{l}$ MyTaq DNA polymerase (Bioline) and $15 \mathrm{ng} / \mu \mathrm{l}$ of DNA template.
PCR reactions were set up in a mastercycler Nexers thermal cycler (Eppendorf). The cycling conditions involved an initial denaturation step at $95^{\circ} \mathrm{C}$ for $10 \mathrm{~min}, 35$ cycles of denaturation step at $94{ }^{\circ} \mathrm{C}$ for $1 \mathrm{~min}$, an annealing step of $54{ }^{\circ} \mathrm{C}$ for $1 \mathrm{~min}$ and an extension step at $72{ }^{\circ} \mathrm{C}$ for $1 \mathrm{~min}$ followed by a final extension at $72{ }^{\circ} \mathrm{C}$ for $10 \mathrm{~min}$ (Gusmão et al., 2007). The expected product size ranged between 450-600 bp.

To target the bacterial small sub-unit rRNA genes from the V1 to the V2 hyper variable region, the PCR amplification for bacteria was carried out using $27 \mathrm{~F}$ (5' AGAGTTTGATCMTGGCTCAG $\left.3^{\prime}\right)$ and 1492R (5' TACCTTGTTACGACGACTT 3') primers (Rinttilä et al., 2004). The PCR reactions set up was as described above except for the annealing temperature at $52{ }^{\circ} \mathrm{C}$. The expected product size was approximately $1,500 \mathrm{bp}$. The amplified PCR products were resolved through a 1.2\% agarose gel. Bands of DNA on the gel were analysed using KETA GL imaging system trans illuminator (Wealtec Corp, Meadowvale Way Sparks, NV, USA).

\section{Sequencing of DNA and species identification}

Successfully amplified products were sent to Macrogen Inc Europe Laboratory, Amsterdam, the Netherlands, for bi-directional sequencing. Bacteria and fungi were then identified by assembling sequences using BioEdit Sequence Alignment Editor Version 7.2.5 then multiple alignment done in Clustal X version 2.1 (Thompson et al., 1997). The sequences were queried via Basic Local Alignment Search Tool (BLAST) at the GenBank database National Centre for Biotechnology Information (NCBI, 2015) for final identification. Sequences of identified microbes were deposited in GenBank (Supplementary Table S1).

\section{Data analysis}

Data on bacterial and fungal loads, expressed as $\log \mathrm{cfu} / \mathrm{g}$, were tested for normality by plotting normal distribution curves and determining the homogeneity of variance. Because the data were normally distributed, one-way analysis of variance with $95 \%$ confidence interval was performed to test for significant differences in microbial counts at different sampling points. The sampling points considered were whole insects from the wild vegetation, trapping sites and markets; and plucked and deep-fried insects from markets. For whole $R$. differens marketed in Kampala, differences in microbial loads in samples originating from Kabale, Fort portal and Kasese districts were determined. Means were separated using Bonferroni adjustment. A two-sample t-test was used to determine if bacterial and fungal counts were significantly different between samples from Kampala and Masaka. All analyses were carried out in R-statistical computer program version 4.0.0 (R Development Core Team, 2019) at $\alpha=0.05$. 


\section{Results}

\section{Bacterial and fungal loads in Ruspolia differens from different sampling points}

The mean bacterial counts in $R$. differens samples varied significantly with sampling points in both the first $\left(\mathrm{F}_{2,43}=91,027, P<0.001\right)$ and second $\left(\mathrm{F}_{4,46}=33,954, P<0.001\right)$ swarming seasons of 2019. The bacterial counts in deep fried $R$. differens were significantly lower than those in raw samples from all other sampling points in both seasons (Figure 2A). The bacterial counts in whole $R$. differens samples from the market in the second season were significantly higher than those in plucked samples in the market, and whole samples from trapping points and the wild vegetation.

There were also significant differences in fungal counts in $R$. differens from different sampling points in both swarming seasons $\left(\mathrm{F}_{4,44}=5,973, P<0.001\right.$ and $\mathrm{F}_{4,46}=3,509, P<0.001$ for first and second seasons, respectively). The fungal counts in fried $R$. differens were significantly lower than those in raw samples from all sampling points (Figure 2B). There were however no significant differences in fungal counts in raw $R$. differens samples from all sampling points in both seasons.

\section{Bacterial and fungal loads in Ruspolia differens samples from Kampala and Masaka}

In the first season, the mean bacterial counts in $R$. differens samples from Masaka were significantly higher than those in samples from Kampala $(\mathrm{t}=7.3, P<0.001)$; Figure $3 \mathrm{~A})$. However, there was no significant difference in bacterial counts in $R$. differens samples between the two districts in the second season $(\mathrm{t}=0.29, P=0.83)$. On the other hand, the mean fungal counts in $R$. differens samples were not significantly different between Masaka and Kampala in both first and second swarming seasons $(\mathrm{t}=1.06, P=0.63$ and $\mathrm{t}=1.32, P=0.12$ respectively; Figure $3 \mathrm{~B})$.

\section{Bacterial and fungal loads in whole Ruspolia differens samples from distribution points in Kampala}

Samples of whole $R$. differens from distribution points in Kampala were found to originate from Fort-portal, Kasese and Kabale districts. There were no significant differences in bacterial counts in whole $R$. differens samples from the distribution points based on the district of origin $\left(\mathrm{F}_{2,6}=1.81\right.$, $P=0.24 ; \sim 8.1 \log \mathrm{cfu} / \mathrm{g}$ for all samples). Similarly, there were no significant difference in fungal counts in whole $R$. differens samples from the distribution points $\left(\mathrm{F}_{2,6}=0.63\right.$, $P=0.56 ; \sim 5.9 \mathrm{cfu} / \mathrm{g}$ for all samples).

\section{Species characterisation of fungi and bacteria in Ruspolia differens samples}

A total of 49 sequences were matched for identity with sequences of the data base and all showed an identity similarity of between 90 and $100 \%$ to the sequences in the GeneBank. Thirty of these sequences originated from pure fungal isolates while 19 came from pure bacterial isolates. From the isolates, 7 species each of bacteria and fungi were recorded (Figure 4; Supplementary Table S1). There were variations in the distribution of microbial species and strains at different sampling points. The highest numbers of bacterial (05) and fungal (04) species were recorded in
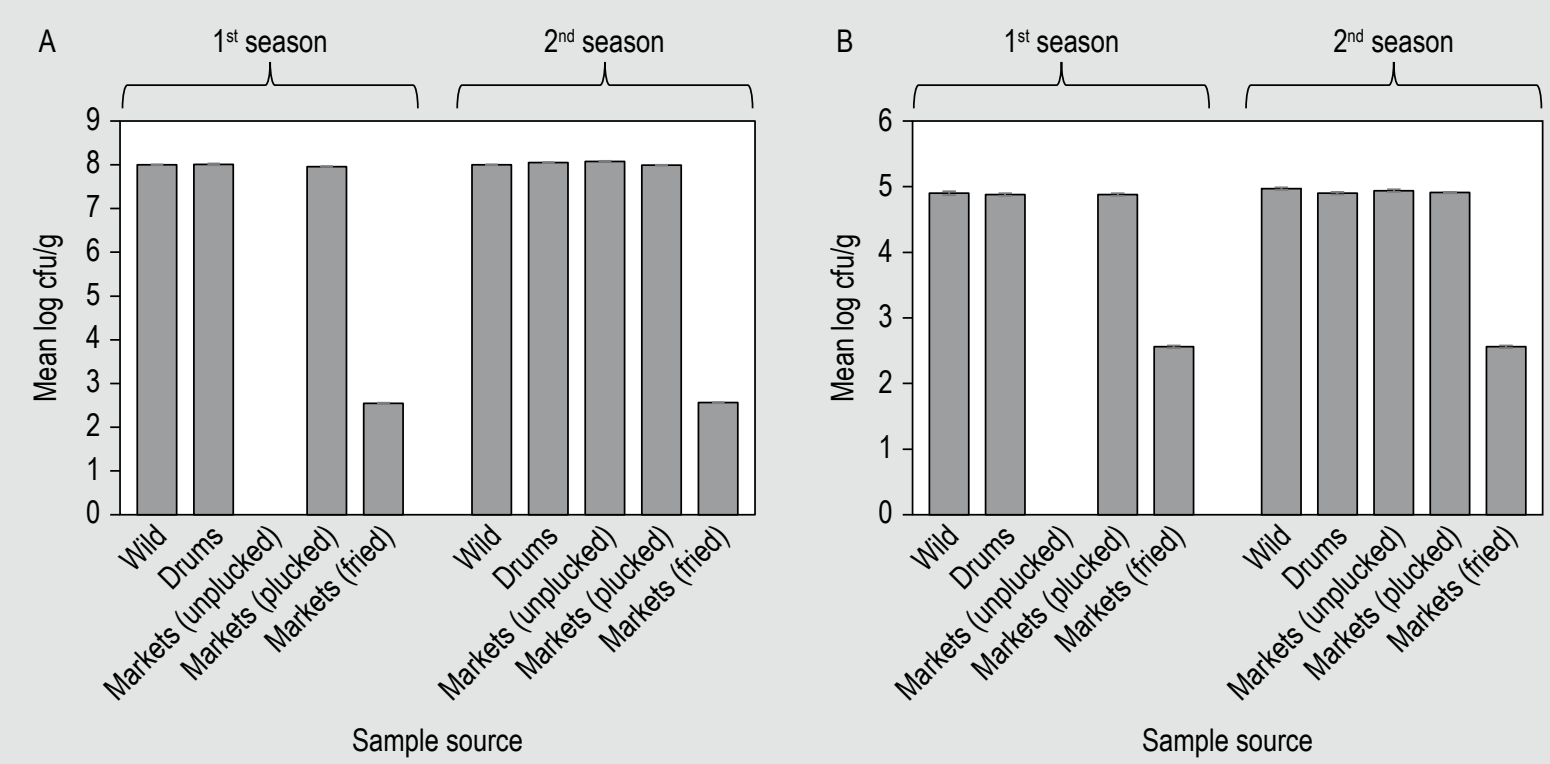

Figure 2. Mean (A) bacterial and (B) fungal counts in Ruspolia differens from different sampling points in Uganda in the first and second seasons of 2019. Error bars represent standard errors of the mean. 


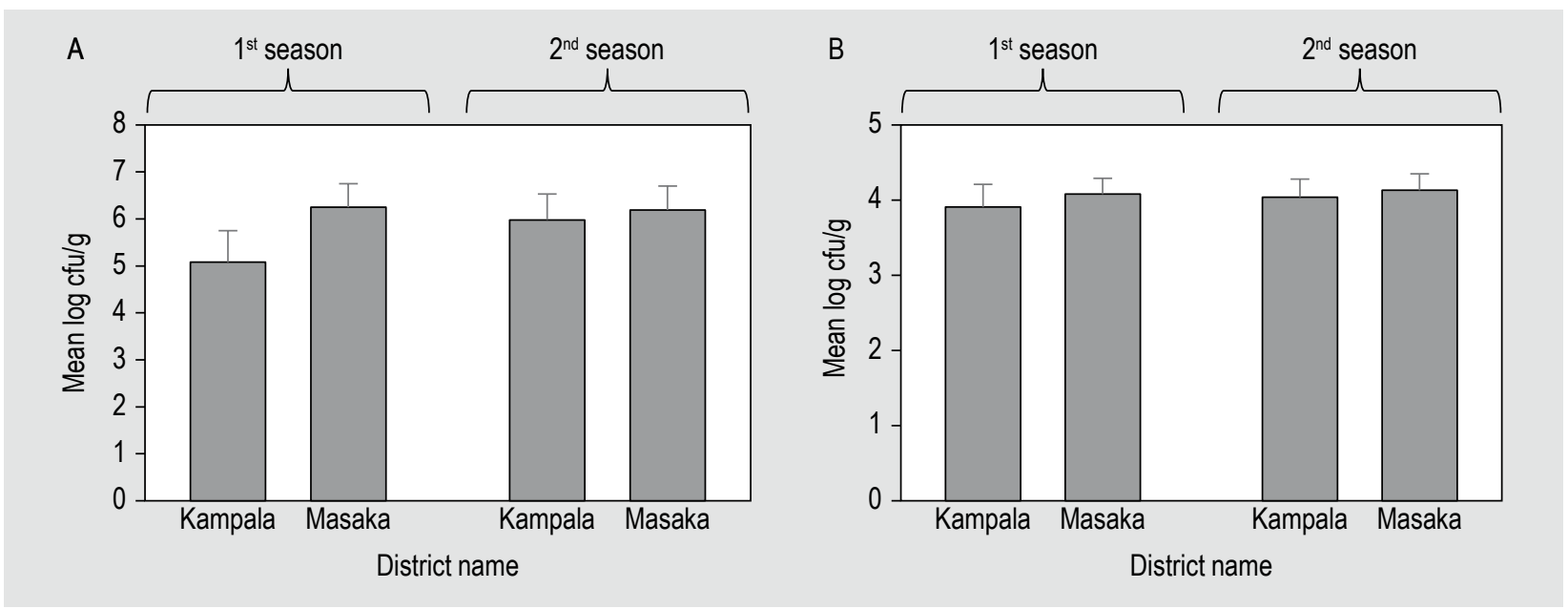

Figure 3. Mean (A) bacterial and (B) fungal counts in Ruspolia differens samples from Masaka and Kampala in the first and second seasons of 2019. Error bars represent standard errors of the mean.

R. differens samples from harvesting drums at trapping sites and the lowest (01 species for both) were recorded in fried ready-to-eat insects from the markets.

Only one bacterial species (Bacillus cereus with 6 strains) was recorded at all sampling points. Staphylococcus sp. (1 strain) and Bacillus thuringiensis (2 strains) were only recorded in harvesting drums at trapping sites, Acinetobacter baumannii at distribution points, whereas Roseomonas sp. (1 strain) was recorded only in plucked samples sold at markets. The fungal species Trichoderma asperellum (with 9 strains) was recorded at all sampling points; while Papiliotrema laurentii (1 strain) was recorded only in whole samples from the wild vegetation. Most species recorded in samples from trapping sites and distribution points or markets were not recorded from insects collected from the wild vegetation (Figure 4). The pathogenic bacterium B. cereus and the fungus T. asperellum were recorded in fried ready-to-eat insects and in plucked samples sold at markets.

\section{Discussion}

High levels of bacterial and fungal contaminants have been previously recorded in wild-harvested edible $R$. differens (Ng'ang'a et al., 2019; Ssepuuya et al., 2019). However, prior to this study, levels of these microbes at different points of $R$. differens handling chain in Uganda had not yet been determined to identify high health risk points. The loads and identity of bacteria and fungi in raw samples of whole $R$. differens from the wild vegetation, trapping sites and at markets, as well as processed (plucked and deep fried) samples from markets during two swarming seasons in 2019 at Masaka and Kampala districts, central Uganda were determined in this study.

Our data show that bacterial counts were significantly higher in whole $R$. differens samples from distribution points than in plucked samples in the markets, and whole samples from the trapping points and the wild vegetation. Potential sources of contamination of $R$. differens at the distribution points are market environment, confinement in bags and human handling. Oranusi and Braide (2012) and Musundire et al. (2016) reported that primitive and unhygienic methods of handling, packaging and storage of edible insects cause contamination with microbes. The significant decline in bacterial counts in raw $R$. differens after plucking in the market could be attributed to extraneous contamination from the environments and handlers, which could most likely settle on appendages which are removed during plucking.

Unlike bacteria, the fungal counts in raw $R$. differens at different sampling points were not statistically different. Fungal growth turn-over rates take hundreds of days unlike bacteria with turn-over rates of hours to few days (Rousk and Bååth, 2011). Therefore, it is unlikely for the fungal populations to change drastically from the time $R$. differens is moved from the wild vegetation to the traps, to the time they are plucked in the market, which takes 1-2 days. The use of relative abundance of colony forming units along $R$. differens handling chain may therefore not suffice in determining high risk points for fungal contaminants.

The bacterial and fungal counts in deep fried ready-to-eat $R$. differens were 3- and 2-fold lower, respectively, than in raw insects at all sampling points. This could be attributed to the efficiency of deep frying in reducing microbial loads in edible insects (Gatheru et al., 2019). The deep fried $R$. differens had lower bacterial and fungal counts (approximately $3 \log \mathrm{cfu} / \mathrm{g}$ ) than the maximum limits of $5 \log \mathrm{cfu} / \mathrm{g}$ and 2-3 log cfu/g set out in the standards on edible insect products in Uganda and Kenya (KEBS, 2020; UNBS, 2020). These maximum limits are comparable with those of minced meat which are recommended for use in 
Contaminant microbe

Gram positive bacteria

Bacillus cereus

Bacillus thuringiensis

Staphylococcus $s p$. strain

Staphylococcus sciuri

Gram negative bacteria

Serratia marcescens

Acinetobacter baumannii

Roseomonas sp.

Basidiomycota

Rhodotorula muscilaginosa

Rhodotorula dairenensis

Trichosporon asahii

Papiiliotrema laurentii

Ascomycota

Trichoderma asperellum

Clavisospora lusitaniae

Pichia kudriavzevii
Whole insect

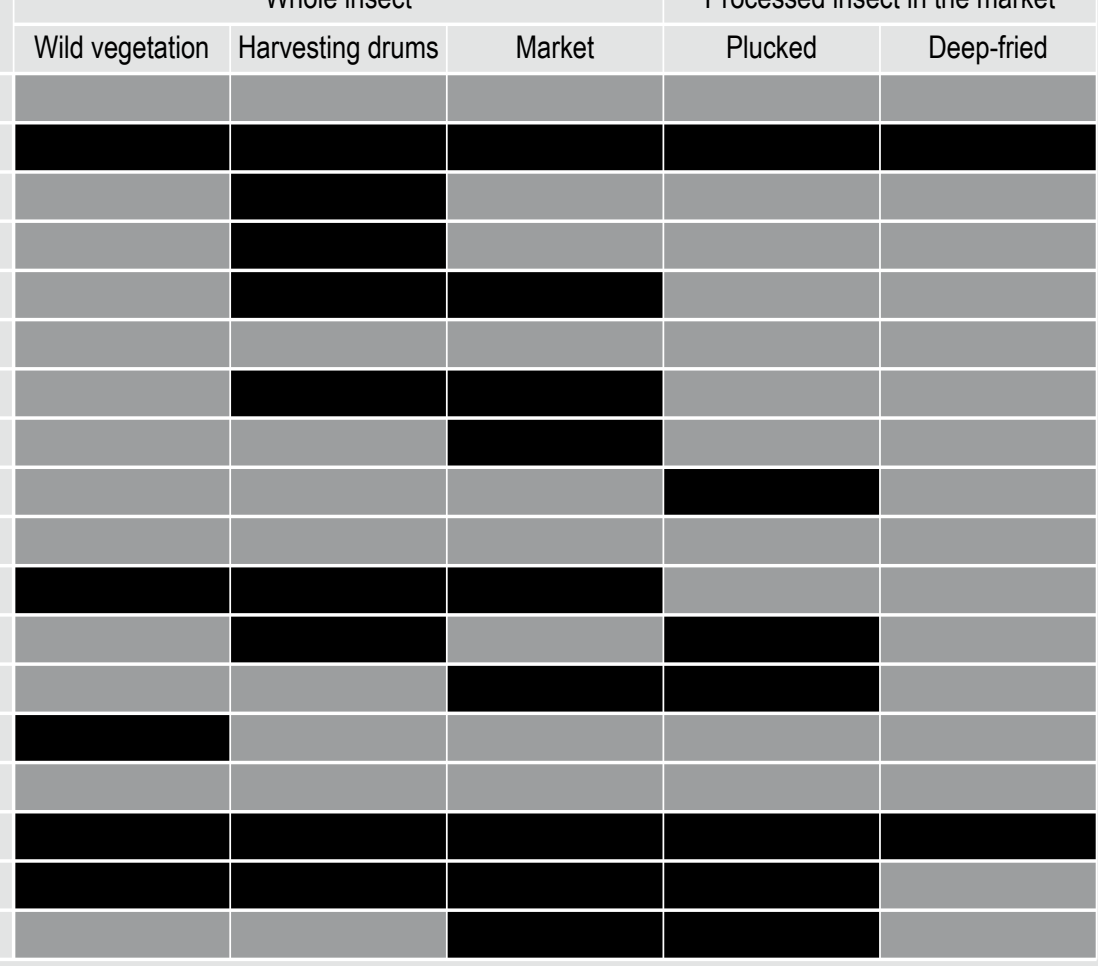

Figure 4. Bacterial and fungal species isolated from Ruspolia differens at different sampling points.

edible insects in many parts of the world (FAO/WHO, 2002; Ssepuuya et al., 2019; Stoops et al., 2016; UNBS, 2019). Despite the low bacterial and fungal counts in deep fried ready-to-eat $R$. differens sold in Ugandan markets, the presence of $B$. cereus may compromise its safety for human consumption. Efforts aimed at eliminating/ preventing recontamination of deep fried ready-to-eat $R$. differens with these microbes are therefore necessary for their safety. Further research is also required to examine the effect of other factors like packaging procedure, duration of sale and hygienic practices of handlers on bacterial and fungal loads in deep fried $R$. differens. On the other hand, the bacterial and fungal counts in raw $R$. differens were higher than the limits recommended for minced meat suggesting that the consumption of raw $R$. differens as practiced by some people in Uganda (Agea et al., 2008), is unsafe. This could be attributed to the high nutrient and moisture content in $R$. differens (Kinyuru et al., 2010), which provides a conducive atmosphere for microbial contamination, growth and survival (Klunder et al., 2012).

There was no detectable difference in fungal counts in $R$. differens collected from Masaka and Kampala during both swarming seasons. However, the bacterial counts in samples from Masaka were significantly higher than in those from Kampala during the first season only. The first rainy season in Uganda is normally wetter than the second season (Nsubuga et al., 2014), which may account for the different results in the two seasons. This finding partly corroborates the report by Bagumire and Karumuna (2017) that microbial loads in ready-to-eat meat sold along high ways in Uganda during the wet season were higher than in the dry season. The specific reasons for the higher bacterial counts in $R$. differens samples from Masaka than those from Kampala in the first season remain unknown.

This study further established that the bacterial and fungal counts in whole $R$. differens at distribution points in Kampala were not influenced by their district of origin. Ssepuuya et al. (2019) reported that $R$. differens traders in Uganda normally buy and package freshly harvested insects in bags and transport them by public means to distribution points. The similarity in packaging, storage and transportation practices across traders may account for the observed similar level of bacterial and fungal contamination of raw whole $R$. differens, irrespective of the district of origin.

Marked variation in number of bacterial and fungal species and/or strains were recorded at different $R$. differens sampling points. This could be attributed to adaptive dynamic shifts in response to changes in niche/community composition (Levy and Borenstein, 2013). The pathogenic bacteria (Staphylococcus sp., Staphylococcus sciuri, B. thuringiensis and Serratia marcescens) and fungus (Rhodotorula dairenensis) 
were recorded in $R$. differens samples from the harvesting drums and not in samples from the wild vegetation. This could be attributed to unhygienic practices during trapping such as smearing drum walls and iron sheets with moist cassava flour to prevent escape of the catch (Okia et al., 2017). Cassava flour processed under unhygienic conditions could be contaminated with microbes including those that produce mycotoxins (Kaaya and Eboku, 2010; Omara et al., 2020). Furthermore, some bacteria such as Staphylococcus spp. and Bacillus spp. have been recorded in dry cassava flour (Ogori and Gana, 2013). Therefore, application of unhygienic moist cassava flour into $R$. differens harvesting drums may be an important entry point for these microbes. Bacillus spp. have also been detected in other edible insects (e.g. Oryctes monoceros (Banjo et al., 2006), Scapsipedus icipe (Gatheru et al., 2017) and T. molitor (Klunder et al., 2012)). Bacillus spp. are a threat to human health and are known to cause food spoilage (Klunder et al., 2012; Stoops et al., 2016; Van Huis et al., 2013). S. marcescens - an opportunistic pathogen (Khanna et al., 2013), may also probably gain entry into $R$. differens through injuries sustained when they struggle to escape from harvesting drums or from manual handling by humans. Other pathogens possibly on non-target species trapped with $R$. differens (Sengendo et al., 2021), could also be additional sources of microbial contamination. This could further explain the relatively high number of bacterial species recorded in samples from the harvesting drums than from the wild vegetation.

The bacterium B. cereus present at all $R$. differens sampling points is associated with many insect taxa, aiding their survival by synthesising essential nutrients (Khanna et al., 2013). $R$. differens trapped with other by-catches could have been contaminated by insects containing these microbes and possibly upon contact with soil. The presence of $B$. cereus in deep fried ready-to-eat $R$. differens could be attributed to their ubiquitous nature (Podschun et al., 2001) coupled with unhygienic practices which predispose the insects to such contaminants. Ssepuuya et al. (2016) reported that $R$. differens vended in transparent polythene bags/plastic buckets were often left open to attract buyers, which exposes the insects to environmental contaminants. Klunder et al. (2012) noted that some Bacillus spp. are resistant to heat treatment and hence could be found in ready-to-eat-foods, causing food spoilage or health problems to consumers.

The presence of A. baumannii and Trichosporon asahii in samples from distribution points but not in samples from the wild vegetation and harvesting drums suggests that they could have been picked up during transportation. Also, Roseomonas sp. recorded in plucked samples only suggests that it could have been introduced during plucking, possibly upon contact with contaminated soil/water (Sandoe and Malnick, 1997). The risk of food contamination with pathogens increases with a long chain of food handlers (Woh et al., 2017).

The pathogenic bacteria S. marcescens and Staphylococcus spp. were detected in $R$. differens from all sampling points except in wild-collected insects. This could be attributed to contamination arising from handling by different people (some of whom may not practice proper personal hygiene) at the different points of the food handling chain (Banjo et al., 2006).

As much as the bacterial and fungal counts in deep fried $R$. differens were below the maximum standard limits of minced meat, the presence of the foodborne pathogen B. cereus, S. marcescens and Staphylococcus spp. is a safety concern that needs to be addressed. Moreover, the vending practices of these foods in open buckets/polythene bags to attract buyers exposes them to environmental contaminants which reduces on their shelf life and causes health risks to consumers (Ssepuuya et al., 2016). Further research for economically feasible innovations of packaging and storing $R$. differens traded in markets/streets, as well as strict regulations on handling the insects are required.

Only one fungal species, $P$. laurentii was isolated exclusively from wild-caught $R$. differens. $P$. laurentii is ubiquitous and prevalent in the soil rhizosphere, where it assimilates a wide range of hexoses, pentoses and organic acids (Leguina et al., 2019). The natural interaction of $P$. laurentii with $R$. differens requires further investigation.

\section{Conclusions}

This study has revealed that bacterial and fungal counts in deep-fried ready-to-eat $R$. differens sold in Uganda were markedly lower than in raw insects and the former are within recommended food safety limits. The highest total bacterial counts were detected in whole samples in the markets followed by whole samples collected from the harvesting drums. The fungal counts in raw $R$. differens were comparable at all sampling points. The bacterial counts in $R$. differens were higher in Masaka than Kampala in the first season only. The bacterial and fungal counts in $R$. differens in Kampala were not influenced by district of origin. Seven species of bacteria and seven species of fungi were recorded in $R$. differens samples. The microbial species were most diverse in samples from trapping points and least diverse in the deep-fried insects. The key foodborne bacterial pathogens detected in $R$. differens samples were B. cereus, S. sciuri, A. baumannii, Staphylococcus sp. strain and $S$. marcescens, of which only $B$. cereus was present in wild-caught whole insect samples. These findings suggest that distribution and trapping points are hotspots for contamination of $R$. differens with microbes, and that processing the insects by plucking and deep frying significantly reduces microbial contamination. Further 
studies are warranted to elucidate specific handling practices at distribution and trapping points which may prevent introduction of microbes into $R$. differens.

\section{Acknowledgements}

This research was funded by the German Federal Ministry for Economic Cooperation and Development (BMZ) commissioned and administered through the Deutsche Gesellschaft für Internationale Zusammenarbeit (GIZ) Fund for International Agricultural Research (FIA), grant number: 012345678 and Bioinnovate Africa Programme (INSBIZ - Contribution ID No. 51050076). We also gratefully acknowledge icipe's core funding provided by United Kingdom's Foreign, Commonwealth \& Development Office (FCDO); the Swedish International Development Cooperation Agency (Sida); the Swiss Agency for Development and Cooperation (SDC); the Federal Democratic Republic of Ethiopia; and the Government of the Republic of Kenya. The views expressed herein do not necessarily reflect the official opinion of the donors.

\section{Conflict of interest}

The authors declare no conflict of interest.

\section{Supplementary material}

Supplementary material can be found online at https://doi. org/10.3920/JIFF2020.0069.

Table S1. Diversity of microbes isolated from Ruspolia differens at different sampling points in Uganda in 2019.

\section{References}

Agea, J.G., Biryomumaisho, D., Buyinza, M. and Nsubuga, G.N., 2008. Commercialization of Ruspolia ntidula (Nsenene grasshoppers) in central Uganda. African Journal of Food Agriculture Nutrition and Development 8: 319-332.

Ayieko, M.A., Kinyuru, J.N., Ndong'a, M.F. and Kenji, G.M., 2012. Nutritional value and consumption of black ants (Carebara vidua Smith) from the lake Victoria region in Kenya. Advanced Journal of Food Science and Technology 4: 39-45.

Bagumire, A. and Karumuna, R. 2017. Bacterial contamination of ready-to-eat meats vended in highway markets in Uganda. African Journal of Food Science 6: 160-170. https://doi.org/10.5897/ AJFS2016.1550

Banjo, A.D., Lawal, O.A. and Songonuga, E.A., 2006. The nutritional value of fourteen species of edible insects in southwestern Nigeria. African Journal of Biotechnology 5: 298-301. https://doi. org/10.5897/AJB05.250
Belluco, S., Losasso, C., Maggioletti, M., Alonzi, C.C., Paoletti, M.G. and Ricci, A., 2013. Edible insects in a food safety and nutritional perspective: a critical review. Comprehensive Reviews in Food Science and Food Safety 12: 296-313. https://doi.org/10.1111/15414337.12014

Bokulich, N.A., Lewis, Z.T., Boundy-Mills, K. and Mills, D.A., 2016. A new perspective on microbial landscapes within food production. Current Opinion in Botechnology 37: 182-189. https://doi. org/10.1016/j.copbio.2015.12.008

Charpe, A.M., Sedani, S.R., Murumkar, R.P. and Bhad, R.G., 2019. Effect of temperature on microbial growth in food during storage. Multilogic in Science 8: 56-58.

Colman, D.R., Toolson, E.C. and Takacs-Vesbach, C., 2012. Do diet and taxonomy influence insect gut bacterial communities? Molecular Ecology 20: 5124-5137. https://doi.org/10.1111/j.1365-294X.2012. 05752.x

Dobermann, D., Swift, J.A. and Field, L.M., 2017. Opportunities and hurdles of edible insects for food and feed. Nutrition Bulletin 42: 293-308. https://doi.org/10.1111/nbu.12291

Engels, P. and Moran, N.A., 2013. The gut microbiota of insects - diversity in structure and function. Federation of European Microbiology Society Reviews 37: 699-735.

Food and Agriculture Organisation / World Health Organisation (FAO/WHO), 2002. Joint FAO/WHO food standards programme codex coordinating committee for the near east: second session. Codex Alimentarius Commission, FAO/WHO, Rome/Geneva, Italy/Switzerland. Available at: http://www.fao.org/fileadmin/ user_upload/gmfp/docs/Codex\%20working\%20paper\%20on\%20 elaboration\%20of\%20a\%20regional\%20standard\%20for\%20 microbiological\%20levels\%20in\%20foodstuffs\%20(CX-NEA\%20 03-16)\%201.pdf

Garofalo, C., Milanović, V., Cardinali, F., Aquilanti, L., Clementi, F. and Osimani, A., 2019. Current knowledge on the microbiota of edible insects intended for human consumption: a state-of-the-art review. Food Research International 9: 108527. https://doi.org/10.1016/j. foodres.2019.108527

Garofalo, C., Osimani, A., Milanović, V., Taccari, M., Cardinali, F., Aquilanti, L., Riolo, P., Ruschioni, S., Isidoro, N. and Clementi, F., 2017. The microbiota of marketed processed edible insects as revealed by high-throughput sequencing. Food Microbiology 62: 15-22.

Gatheru, J.W., Khamis, F.M., Ombura, F.L.O., Nonoh, J., Tanga, C.M., Maina, J., Mohamed, S.A., Subramanian, S., Ekesi, S. and Fiaboe, K.K.M., 2019. Impact of processing methods on microbial load of reared and wild-caught edible crickets (Scapsipedus icipe and Gryllus bimaculatus) in Kenya. Journal of Insects as Food and Feed 5: 171-183.

Gusmão, D.S., Santos, V.A., Marini, D.C., De Souza, E.R., Peixoto, A.M., Bacci, M.J., Berbert-molina, M.A. and Lemos, A.J.F., 2007. First isolation of microorganisms from the gut diverticulum of Aedes aegypti (Diptera : Culicidae): new perspectives for an insect-bacteria association. Memorias do Instituto Oswaldo Cruz 102: 919-924.

Kaaya, A.N. and Eboku, D., 2010. Mould and aflatoxin contamination of dried cassava chips in Eastern Uganda: association with traditional processing and storage practices. Journal of Biological Sciences 10: 718-729 
Kelemu, S., Niassy, S., Torto, B., Fiabo, K., Affogon, H., Tonnang, H., Maniania, N.K. and Ekesi, S., 2015. African edible insects for food and feed: inventory, diversity, commonalities and contribution to food security. Journal of Insects as Food and Feed 1: 103-119. https://doi.org/10.3920/JIFF2014.0016

Kenya Bureau of Standards (KEBS), 2020. Edible insect's products - specification DKS 2922-1:2020: ICS 67.120. KEBS, Nairobi, Kenya. Available at: https://www.kebs.org/images/standards/ public_review_standards/2020/june/dks_2922part_1_2020_edible_ insects_products_pr.pdf

Khanna, A., Khanna, M. and Aggarwal, A., 2013. Serratia marcescens - a rare opportunistic nosocomial pathogen and measures to limit its spread in hospitalized patients. Journal of Clinical and Diagnostic Research 7: 243-246. https://doi.org/10.7860/JCDR/2013/5010.2737

Kinyuru, J.N., Kenji, G., Muhoh, S.N. and Ayieko, M., 2010. Nutritional potential of longhorn grasshopper (Ruspolia differens) consumed in Siaya district, Kenya. Journal of Agriculture, Science and Technology 12: 32-46.

Klunder, H.C., Wolkers-Rooijackers, J., Korpela, J.M. and Nout, M.J.R., 2012. Microbiological aspects of processing and storage of edible insects. Food Control 26: 628-631. https://doi.org/10.1016/j. foodcont.2012.02.013

Leguina, A.C.D.V., Barrios, A.C., Soro, M.D.M.R., Lacosegliaz, M.J., Pajot, H.F., De Figueroa, L.I.C. and Nieto-Peñalver, C.G., 2019. Copper alters the physiology of tomato rhizospheric isolates of Papiliotrema laurentii. Scientia Horticulturae 243: 376-384.

Leonard, A., Khamis, F.M., Egonyu, J.P., Kyamanywa, S., Ekesi, S., Tanga, C.M., Copeland, R.S. and Subramanian, S., 2020. Identification of edible short-and long-horned grasshoppers and their host plants in East Africa. Journal of Economic Entomology 113: 2150-2162. https://doi.org/10.1093/jee/toaa166

Levy, R. and Borenstein, E., 2013. Metabolic modeling of species interaction in the human microbiome elucidates community-level assembly rules. Proceedings of the National Academy of Sciences 110: 12804-12809.

Masaka District Local Government, 2020. Geographical features. Available at: https://masaka.go.ug/content/geographical-features

Mmari, M.W., Kinyuru, J.N., Laswai, H.S. and Okoth, J.K., 2017. Traditions, beliefs and indigenous technologies in connection with the edible longhorn grasshopper Ruspolia differens (Serville 1838) in Tanzania. Journal of Ethnobiology and Ethnomedicine 13: 60. https://doi.org/10.1186/s13002-017-0191-6

Musundire, R., Osuga, I.M., Cheseto, X., Irungu, J. and Torto, B., 2016. Aflatoxin contamination detected in nutrient and anti-oxidant rich edible stink bug stored in recycled grain containers. PLoS ONE 11: e0145914. https://doi.org/10.1371/journal.pone.0145914

National Centre for Biotechnology Information (NCBI), 2015. Nucleotide BLAST: search nucleotide databases using a nucleotide query. Basic local alignment search tool. NCBI, Bethesda, MD, USA. Available at: https://www.ncbi.nlm.nih.gov/genome/seq/BlastGen/ BlastGen.cgi?taxid $=9823$

National Environment Management Authority (NEMA), 2014. National state of the environment report for Uganda 2014: harnessing our environment as infrastructure for sustainable livelihood and development. NEMA, Kampala, Uganda.
Ng'ang'a, J., Imathiu, S., Fombong, F., Ayieko, M., Vanden Broeck, J. and Kinyuru, J., 2019. Microbial quality of edible grasshoppers Ruspolia differens (Orthoptera : Tettigoniidae): from wild harvesting to fork in the Kagera Region, Tanzania. Journal of Food Safety 39: 1-6. https://doi.org/10.1111/jfs.12549

Nsubuga, F.W.N., Botai, O.J., Olwoch, J.M., Rautenbach, C.J., Bevis, Y. and Adetunji, A.O., 2014. The nature of rainfall in the main drainage sub-basins of Uganda. Hydrological Sciences Journal 59: 278-299. https://doi.org/10.1080/02626667.2013.804188

Nyangena, N.D., Mutungi, C., Imathiu, S., Kinyuru, J., Affognon, H., Ekesi, S., Nakimbugwe, D. and Komi K.M.F., 2020. Effects of traditional processing techniques on the nutritional and microbiological quality of four edible insect species used for food and feed in East Africa. Journal of Foods 9: 574. https://doi. org/10.3390/foods 9050574

Ogori, A. and Gana, J., 2013. Microbiological loads of road side dried cassava flour from cassava balls and chunks. American Open Journal of Agricultural Research 1: 24-39.

Okia, C.A., Odongo, W., Nzabamwita, P., Ndimubandi, J., Nalika, N. and Nyeko, P., 2017. Local knowledge and practices on use and management of edible insects in Lake Victoria basin, East Africa. Journal of Insects as Food and Feed 3: 83-93. https://doi. org/10.3920/JIFF2016.0051

Omara, T., Nassazi, W., Omute, T., Awath, A., Laker, F., Kalukusu, R., Musau, B., Nakabuye, B.V., Kagoya, S., Otim, G. and Adupa, E. 2020. Aflatoxins in Uganda: an encyclopedic review of the etiology, epidemiology, detection, quantification, exposure assessment, reduction, and control. International Journal of Microbiology, Article ID: 4723612. https://doi.org/10.1155/2020/4723612

Omoya, F.O. and Akinyosoye, F., 2013. Evaluation of the potency of some entomopathogenic bacteria isolated from insect cadavers on Anopheles arabiensis Giles (Order: Diptera; Family: Culicidae) mosquito larvae in Nigeria. African Journal of Microbiology Research 41: 4877-4881. https://doi.org/10.5897/ajmr12.1926

Osimani, A., Garofalo, C., Milanović, V., Taccari, M., Cardinali, F., Aquilanti, L., Pasquini, M., Mozzon, M., Raffaelli, N., Ruschioni, S. and Riolo, P., 2017. Insight into the proximate composition and microbial diversity of edible insects marketed in the European Union. European Food Research and Technology 43: 1157-1171.

Oranusi, S. and Braide, W., 2012. A study of microbial safety of readyto-eat foods vended on highways: Onitsha-Owerri, south east Nigeria. International Research Journal of Microbiology 3: 66-71.

Podschun, R., Pietsch, S., Höller, C. and Ullmann, U., 2001. Incidence of Klebsiella species in surface waters and their expression of virulence factors. Applied and Environmental Microbiology 67: 3325-3327. https://doi.org/10.1128/AEM.67.7.3325-3327.2001

Public Health England, 2019. UK standards for microbiology investigations. Primary health care publications gateway, United Kingdom. Public Health England, London, UK.

R Core Team, 2019. R: a language and environment for statistical computing. R Foundation for Statistical Computing, Vienna, Austria.

Rinttilä, T., Kassinen, A., Malinen, E., Krogius, L. and Palva, A., 2004. Development of an extensive set of 16S rDNA-targeted primers for quantification of pathogenic and indigenous bacteria in faecal samples by real-time PCR. Journal of Applied Microbiology 97: 1166-1177. https://doi.org/10.1111/j.1365-2672.2004.02409.x 
Rousk, J. and Bååth, E., 2011. Growth of saprotrophic fungi and bacteria in soil. FEMS Microbiology Ecology 78: 17-30. https:// doi.org/10.1111/j.1574-6941.2011.01106.x

Sandoe, J.A.T. and Malnick, H., 1997. A case of peritonitis caused by Roseomonas gilardii in a patient undergoing continuous ambulatory peritoneal dialysis. Journal of Clinical Microbiology 35: 2150-2152.

Sengendo, F., Subramanian, S., Chemurot, M., Tanga, C.M. and Egonyu, J.P., 2021. Efficient harvesting of safe edible grasshoppers: evaluation of modified drums and light-emitting diode bulbs for harvesting Ruspolia differens (Orthoptera: Tettigoniidae) in Uganda. Journal of Economic Entomology 114: 676-683. https://doi.org/10.1093/ jee/toab025

Ssepuuya, G., Aringo, R.O., Mukisa, I.M. and Nakimbugwe, D., 2016. Effect of processing, packaging and storage-temperature based hurdles on the shelf stability of sautéed ready-to-eat Ruspolia nitidula. Journal of Insects as Food and Feed 2: 245-253. https:// doi.org/10.3920/JIFF2016.0006

Ssepuuya, G., Wynants, E., Verreth, C., Crauwels, S., Lievens, B., Claes, J., Nakimbugwe, D. and Van Campenhout, L., 2019. Microbial characterisation of the edible grasshopper Ruspolia differens in raw condition after wild-harvesting in Uganda. Food Microbiology 77: 106-117. https://doi.org/10.1016/j.fm.2018.09.005

Ssepuuya, G., Mukisa, I.M. and Nakimbugwe, D., 2017. Nutritional composition, quality, and shelf stability of processed Ruspolia nitidula (edible grasshoppers). Food Science and Nutrition 5: 103112. https://doi.org/10.1002/fsn3.369
Stoops, J., Crauwels, S., Waud, M., Claes, J. and Lievens, B., 2016. Microbial community assessment of mealworm larvae (Tenebrio molitor) and grasshoppers (Locusta migratoria migratorioides) sold for human consumption. Food Microbiology 53: 122-127.

Thompson, J.D., Gibson, T.J., Plewniak, F., Jeanmougin, F. and Higgins, D.G., 1997. The CLUSTAL X windows interface: flexible strategies for multiple sequence alignment aided by quality analysis tools. Nucleic Acids Research 25: 4876-4882. https://doi.org/10.1093/ nar/25.24.4876

Uganda National Bureau of Standards (UNBS), 2020. Draft Uganda standards: edible insect's products - Specification DUS 2146:2019. UNBS, Kampala, Uganda.

Van Huis, A., Van Itterbeeck, J., Klunder, H., Mertens, E., Halloran, A., Muir, G. and Vantomme, P., 2013. Edible insects: future prospects for food and feed security. FAO Forestry Paper 171. FAO, Rome, Italy. Vandeweyer, D., Crauwels, S., Lievens, B. and Van Campenhout, L., 2017. Metagenetic analysis of the bacterial communities of edible insects from diverse production cycles at industrial rearing companies. International Journal of Food Microbiology 261: 11-18.

White, T.J., Bruns, T., Lee, S. and Taylor, J., 1990. Amplification and direct sequencing of fungal ribosomal RNA genes for phylogenetics. In: Innis, M.A., Gelfand, D.H., Sninsky, J.J. and White, T.J. (eds.) PCR protocols: a guide to methods and applications. Academic Press, New York, NY, USA, pp. 315-322.

Woh, P.Y., Thong, K.L., Lim, L.A., Behnke, J.M., Lewis, J.W. and Zain, S.N.M., 2017. Microorganisms as an indicator of hygiene status among migrant food handlers in Peninsular Malaysia. Asian Pacific Journal of Public Health 29: 599-607. https://doi. org/10.1177/1010539517735856 
